\title{
Lesson Study and Its Potential Application in ELT during the Pandemic
}

\author{
Muhammad Amin \\ English Department, \\ University of Mataram, \\ Mataram, Indonesia \\ aminmuhammad@unram.ac.id
}

\begin{abstract}
This paper intends to explore the potentials of implementing Lesson Study (LS), a teacher professional development program which is originally from Japan and has been spreading and practiced globally especially amid COVID19, requiring a lot of adaptation in all sectors including education. The benefits of LS are unquestionable as this type of program has been proven to be effective for improving both students learning (through its emphasis on researching its impacts on students' learning outcomes and use the learning as basis of measuring success of the study) and teacher professional performance (through their participatory and constructive collaboration in planning, implementing and reviewing a lesson). For the teachers, in particular, this program is constructive as it facilitates them to adapt and modify their teaching beliefs and practices in accordance with what has been found to better suit learning of their students. While the procedures and process of implementing LS during the 'normal' situation have been clearly formulated, there have been concerns surrounding the implementation of $L S$ in extraordinary circumstances such as the COVID-19 pandemic. This paper will discuss how LS can still potentially be effective to enhance learning, especially in foreign language teaching. It starts with reviews of the general information about LS, which includes its definition, benefits and challenges in the teaching and learning process in the normal contexts. The subsequent part presents how the pandemic shapes the new contexts of learning in educational institutions, which is then followed by careful examination of possible adaptation of procedures and activities in conducting LS during this pandemic, including in ELT.
\end{abstract}

Key words—lesson study, covid-19 pandemic, ELT

\section{I.THE REALITY OF TEACHING WORLD}

It's been known that the reality of teaching keeps changing. This change is unavoidable because of the contexts of teaching which are prone to changes and in fact they keep changing. The change can be caused by the implementation of new curricula, societal needs, technological advancement and so on. Among the many variables which affect students' learning, teachers are identified to be the most determining one (1) [1]. According to him, the share of this particular variable makes $30 \%$ of the whole variables affecting student learning. Consequently, teachers need to keep adjusting to meet the demands of their daily professional demands. In other words, teachers need to conduct life-long professional development, commonly known as continuing professional development (CPD), and this has been given a lot attention in the last decades (2) [2].

There are basically two types of professional development procedures. The first one is the ones organized by outsiders. Specifically, these types of professional development procedures mostly take place outside of schools and mostly outside teachers' actual workplace (classrooms). Whereas the second type is the professional development procedures that are internalized by the teachers and are usually conducted by themselves too. Among the very common types of activities in the first professional development procedures are attending seminar or conferences and teacher training, workshop or it can be in the form of supervision by school superintendents.

Different from the first type, the teacher-initiated professional is self-initiated. It is more independent of outsiders and hence can be more freely conducted by teachers both in terms of time and place. It is channeled through various activities such as reading books or journal articles on certain topics or teacher professional development or simply talking to and sharing with other fellow teachers. Two other teacher professional development procedures of this type are peer observation or peer-teaching and classroom-based research. In addition to classroom action research (CAR), the one which is very popular among teachers, there is another type of professional development activity focusing on classroom learning. This is known as lesson study or what is commonly known as LS. While the practice of this classroom learning observation is common, there still remains a question concerning the efficacy of this program during the pandemic? The question can be answered by firstly looking at the fundamental principles in the LS.

\section{II.WHAT IS LESSON STUDY?}

Lesson study can be defined as highly specific type of classroom action research focusing on the development of teachers' pedagogy. It is originally introduced in Japan, in 1870s (3), and has been adopted across continents - North America, Asia, Europe and South Africa (4). LS involves a group of people working together to plan, observe and analyze learning and teaching in research lessons. Although the main participants in LS are teachers, other parties such as school management, lecturers from universities and policy makers can also be involved too. Other than teachers, outsiders can be useful in getting and giving more information on what is going on in the classroom as well as enriching perspectives on the reality of classroom practice. In addition, relevant parties (such as school management and policy makers) may give supports to succeed the implementation of LS. School management, for example, can give administrative, financial and material supports whereas policy makers, such as those from governmental educational institution, through their direct observation of classroom 
learning can formulate supportive policies toward the improvement of education quality. Teaching staff from universities can be expected to provide new or different insights of the teaching learning process as they are supposed to be more updated with the development of teaching knowledge and expertise.

There are several reasons for conducting lesson study. The first one is because the main objective of lesson study is to improve student learning. Even when teachers are involved in LS, the goal is still to help students learning which is examined from the teachers' perspectives, followed by the instructional adjustments to meet students' learning needs. Second, it deals with the actual problems emerging in classrooms. So, its focus is on revealing difficulties that students encounter in their learning: identify the problems and find solutions to the problems. The third reason in conducting lesson study is to support teaching and learning community, harboring in optimizing the students' learning . The next reason is information on student learning is more valid due to the fact that there are more observers in the process. The last reason is abundance of valid information on what is really going on student learning will help teachers modify their instructions to suit each student's learning style, which again is the end goal of the program.

\section{III.STAGES IN CONDUCTING LESSON STUDY PROGRAM}

There are some stages in conducting lesson study. First stage is identifying students' learning problem. This may include aspects which can still or need to be improved. After knowing the problems, teachers and other team in LS will work together to propose an instructional plan. The next issue will be implementing/teaching lesson using the proposed technique. At this stage we will have a teacher in charge of delivering the lesson. During this teaching process, some teachers will focus on observing the lesson as a whole and also to closely look at identified case pupils. During this time data on the effect of the planned/proposed solution are collected. After the implementation of teaching in the classroom, the following stage will be to interview the pupils. This will be a good source of data as it provides us with authentic information through the lens of the students. The final stage is reflection. To accomplish the last stage, the LS group will sit together to see the effect of the lesson especially on the targeted students.

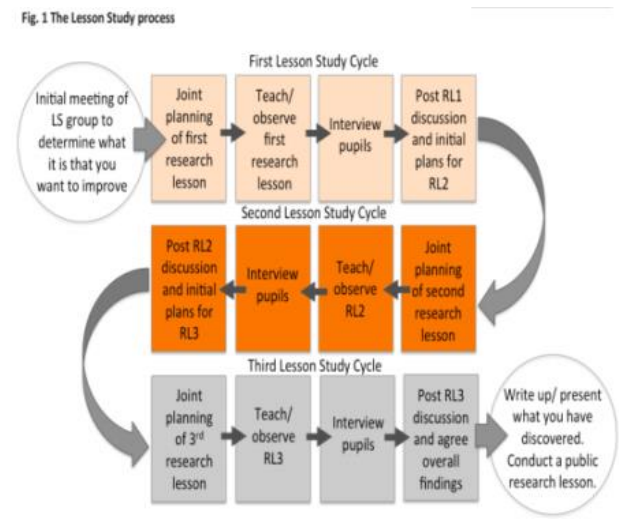

\section{FIG. I. LS PROGRAM}

In order for an LS program to run appropriately, there are some principles of lesson study for participants involved in the study to observe. These principles are also called LS protocol [3]. The following are the guidelines for conducting [4]:

- $\quad$ all members of the LS group are equal as learners whatever their age, experience, expertise or seniority in school (or beyond)

- all contributions are treated with unconditional positive regard - this does not mean they will not be subject to analysis, doubt or challenge, it means no one will be made to feel foolish for venturing a suggestion. It is often suggestions that make you feel foolish or vulnerable that are of the greatest value and generate the most learning

- we will support whoever teaches the research lesson(s) and make faithful observations recording as much as possible what pupils say as well as do

- we will use common tools for lesson study planners, pupil interview prompts and approaches to sharing outcomes with each other

- we will use pupils' work and their interview comments to inform the post lesson discussion alongside our observations

- we will use the post lesson discussion flow starting by discussing what each case pupil did compared with what we predicted and let the discussion flow from there

- we will listen to each other and to ourselves when we speak and build on the discussion making suggestions, raising hypotheses, elaborating, qualifying and at all times being accountable to our lesson aims, our case pupils and our observation and other research lesson data

- we will share what we learn - our new practice knowledge - with our colleagues as accurately and vividly as we can in such a way that they can benefit from and try it out themselves

- we will share the aims and outcomes of our lesson study with our pupils appropriately depending on their ages and stages of development. Their views, ideas and perspectives will be treated with equally positive regard.

Based on the protocol above, it is evident that LS is a teacher initiated professional learning which is based in the classroom, focusing on students learning, conducted by collaborative and supportive LS groups, intended not only for improvement of learning in own classroom but also to be spread to other relevant participants in need. As a whole, however, the success and sustainability of LS depend so much on well-developed systems of leadership and organizational support $(4, \mathrm{p} .47)$ as it is conducted within the area managed and organized by a school system.

\section{IV.ADVANTAGES AND CONSTRAINTS OF CONDUCTING LESSON STUDY}

The effects of LS are not just limited to students' improved learning in school but also the broader contexts of education as it can be "used across schools and beyond as they can collaborate and learn together with their university, college and other partners". If conducted appropriately, it can 
positively affect learning, schools, initial and continuing teacher education as well as enhancing curriculum, assessment, leadership and the whole education system. Teachers having participated in LS assert that they can respond more appropriately to pupils' learning through better use of their initial knowledge and understanding (Fernandez in [5]. Dudley also cited 22 studies showing evidence of benefits of LS on improved quality of classroom teaching and learning which include quality of classroom practice and improvement in students learning [4]. In addition, they also found from the review that the subjects where LS is implemented vary from those which it was first focused on (math and science), to other subjects such as English as a Second Language (ESL), literacy, humanities, and business and economics.

Despite its various benefits, there are several constraints identified in conducting LS. Among the very common ones are time available to participate in LS [6]-[8]. This lack of time availability is mostly caused by the teachers' busy teaching schedule. (One example is in Japan at least $10 \%$ of teachers of primary schools spent 16 hours a day and 14.5 hours for secondary teachers) [6]. Another constraint is the extra stress and demands that a teacher requires to handle when conducting this type of professional development [9]. The other two obstacles of implementing LS are lack of strong leadership supports to allow teachers to participate and sustain this professional development activity and feeling in the comfort zones among teachers and school management for any new change in classroom and school culture [10].

\section{V.LESSON STUDY DURING THE PANDEMIC}

The teaching and learning process should continue regardless of the situation and so does it happen during the outbreak of novel corona virus-19. While it was true that there was a short closure of access to learning from schools and other education institutions at the beginning stage of the pandemic, these education institutions have been trying to adapt to the new situation in order to keep the learning process going [11]. In their study, Arlinwibowo and colleagues found that teachers agreed to find alternative to help students learn, one of which was to conduct online learning [12].

Just as in the face-to-face learning, online learning is never absent of problems and the number and types of problems faced vary even more considerably. While we have been quite familiar with learning problems in the face-to-face contexts, this pandemic has brought with it more varied problems, many of which have never been imagined before (remember we did not anticipate the closure of schools as a result of covd-19 breakout or that we would conduct an international conference by having all speakers present their topics online).Some of the very urgent obstacles of online learning are in forms of "producing learning media and making fair assessment plan', conducting the online learning itself due to problems with internet-related problems [12] and availability of online learning devices and applications and how to utilize them on both teachers' and students' sides (personal experience and observation). In short, teaching and learning problems encountered during the pandemic still exist and surely need to be addressed and LS which has been proven to be quite effective in solving classroom learning problems is worth consideration.

\section{VI.APPLYING LS IN ELT CLASSROOM DURING THE PANDEMIC}

As has been mentioned earlier, many schools and institutions have opted to move to online learning instead of face-to-face to keep teaching and learning process going. Of course, this change has forced teachers and school management to find ways and strategies to optimize learning. Teachers and students now have to conduct their lessons using different facilities and teaching methods. In online mode, all parties engaged in the learning process cannot avoid typical features of this new model. These features include use of the internet and technological devices and also absence of-face-to face communication. However, despite absence of learning features students and teachers are familiar with and used to utilizing, the main stages of learning should still be accomplished: planning the lesson, implementing it, and assessing the lesson. It can be assumed that if appropriately planned and well supported with what it needs (internet connection, reliable device and skills to use it), a lesson can still successfully be conducted, although not as smoothly as it is in the normal situations. (Through course of time all relevant parties will get used to this new practice of teaching).

As in all other contexts of teaching and learning, in online teaching and learning mode too, there will also be problems with students learning process in general. As this is new, the problems are likely to be more varied and many are not yet identified and will come as the learning process progresses. These problems and difficulties are surely what LS is expected to deal with. With this in mind, we can conclude that LS has, and as it always does, a setting where it is applicable. But how then can it be applied, especially in ELT? In what way(s) can the plan, do and see stages of LS be implemented?

Despite the fact that the learning mode during the pandemic is different, in that the use of online learning is more dominant, all features of successful learning should be present in a lesson. In ELT in particular, aspects of communicative activities, effective target language modelling, learner-centeredness learning should also be taken into account. Therefore, when designing a lesson, a teacher should consider materials, activities, media and methods and assessment which will provide optimum learning opportunities for students. However, as is in the face-to-face learning mode, there are always problems to encounter and solve and rooms for improvement on the side of students learning. This is again what LS is intended to address. The following is an elaboration of how LS stages are accomplished in the online learning mode.

The planning stages of LS can be done using online mode too. This is of course one of the many benefits. All parties involved in the program do not have to meet in person as they can identify the process of teaching and learning without having to come to school. Through their respective observation, they can identify students learning problems and formulate and propose solutions. The team might decide to improve the quality of learning input from the teachers, through a more professional use of media, for example, or find ways to increase the students' participation. Then the team will plan a lesson with the proposed solution and have 
one teacher to teach it. This then will lead to the third stage of LS that is to see or observe the process of teaching and learning with typical procedures of LS observation (see (3)). And again, as this is an online lesson, all observers can conduct the observations online too. Depending on features used in the online meeting, observers can focus on particular learners doing particular activities. (Zoom application, for example, enables learners to be grouped and observers can be added to the groups. Or if an observer aims to focus the observation on particular learner(s), she/he can accomplish this goal simply by zooming them).

In addition to using virtual meeting applications such as zoom, Big Blue Button or google meet, the process of learning can also be monitored through the use of learning management system (LMS) such as the google classroom and moodle. These two LMSs can provide observers information about students' participation during the teaching and learning process as well as the quality of their work, which will be data for LS team to reflect on and discuss to see the extent to which the lesson has been successful. This last stage of LS can also be conducted online using zoom or google meet. In short, LS can still be implemented even during the pandemic where learning is mostly conducted online.

\section{CONCLUSION}

LS is a very useful procedure to improve learning for students, teachers and other relevant parties involved in the program. While it can be successfully implemented during the normal situations, this teacher professional development procedure is also potentially applicable during the pandemic, one typical feature of which is that learning is conducted online, although surely some adaption is required. The main requirement will be students' and LS team's familiarity with online learning features at all stages of LS implementation.

\section{REFERENCES}

[1] J. Hattie, "Teachers Make a Difference, What is the research evidence?," 2003. Accessed: May 11, 2021. [Online]. Available: https://research.acer.edu.au/research_conference_2003.

[2] C. D.-L. S. P. learning for our time and undefined 2015, "Lesson Study as a strategic choice for CPD," books.google.com, Accessed: May 11, 2021. [Online]. Available: https://www.google.com/books?hl=id\&lr=\&id=ppleBAAAQBAJ $\&$ oi $=$ fnd $\& p g=$ PR15\&dq $=$ C. + Desforges,+ Lesson + Study + as + a + St rategic+Choice.+In+Lesson+Study:+Professional+Learning+in+o ur+Time.+Peter+Dudley\&ots $=5 Z$ DSXpxLu3\&sig $=$ mfGcmRQR0 V8rQYEWXXi4d7TdYZM.

[3] P. Dudley, "How Lesson Study works and why it creates excellent learning and teaching," in Lesson Study, Routledge, 2018, pp. 1-28.

[4] P. Dudley, "Lesson Study: professional learning for our time How and why Lesson Study can help to overcome longstanding and intractable barriers to teacher learning and school to school support,” 2013. Accessed: May 11, 2021. [Online]. Available: www.lessonstudy.co.uk

[5] C. Fernandez, "Learning from Japanese Approaches to Professional Development: The Case of Lesson Study On behalf of: American Association of Colleges for Teacher Education (AACTE) can be found at: Journal of Teacher Education Additional services and information for," journals.sagepub.com, vol. 53, no. 5, pp. 393-405, Nov. 2002, doi: $10.1177 / 002248702237394$

[6] E. Aoki, "Kyoin no shigoto wo dou dezain suruka (How to design work of teachers)," Benesse Educ. Res. Dev., no. 14, pp. 13-17, 2008 .

[7] C. Fernandez, "Lesson Study: A Means for Elementary Teachers to Develop the Knowledge of Mathematics Needed for ReformMinded Teaching?," Math. Think. Learn., vol. 7, no. 4, pp. 265289, Oct. 2005, doi: 10.1207/s15327833mt10704_1.

[8] B. Norwich, A. Y.-T. and teacher education, and undefined 2013, "Design based research to develop the teaching of pupils with moderate learning difficulties (MLD): Evaluating lesson study in terms of pupil, teacher and school," Elsevier, Accessed: May 11, 2021. [Online]. Available:

https://www.sciencedirect.com/science/article/pii/S0742051X130 00796.

[9] J. L.-T. and teacher education and undefined 2008, "A Hong Kong case of lesson study-Benefits and concerns," Elsevier, Accessed: May 11, 2021. [Online]. Available: https://www.sciencedirect.com/science/article/pii/S0742051X070 01357.

[10] C. Meng, L. S.-C. Education, and undefined 2011, "Encouraging the innovative use of Geometer's Sketchpad through lesson study," scirp.org, Accessed: May 11, 2021. [Online]. Available: https://www.scirp.org/html/6796.html.

[11] "Education: From disruption to recovery." https://en.unesco.org/covid19/educationresponse (accessed May 11, 2021).

[12] J. Arlinwibowo, H. Retnawati, B. Kartowagiran, and G. K. Kassymova, "Distance learning policy in Indonesia for facing pandemic COVID-19: School reaction and lesson plans," $J$. Theor. Appl. Inf. Technol., vol. 98, no. 14, pp. 2828-2838, 2020. 